\title{
The role of endoscopic therapy in the minimally invasive management of pancreatic necrosis
}

Jeffrey James Easler

Division of Gastroenterology and Hepatology, Indiana University School of Medicine, Indianapolis, IN, USA

Received: October 2, 2020 Accepted: November 2, 2020

\section{Correspondence to} Jeffrey James Easler, M.D. Division of Gastroenterology and Hepatology, Indiana University School of Medicine, 550 N. University Blvd, Suite 1634, Indianapolis, IN 46202, USA

Tel: $+1-3179484978$

Fax: $+1-3179681265$

E-mail:jjeasler@iu.edu

https://orcid.org/0000-0002$3772-2803$

\begin{abstract}
Pancreatic necrosis is among the most frequently encountered local complications of acute pancreatitis and associates with severe disease. Infected pancreatic necrosis further enhances the risk for morbidity and mortality. Pancreatic fluid collections that result from pancreatic necrosis evolve from acute necrotic collections to walled off necrosis and are defined by their distinct characteristics on cross sectional imaging. A variety of interventions spanning multiple disciplines are available for the drainage and debridement of pancreatic necrosis. Prospective, randomized trials have identified management strategies that incorporate minimally invasive interventions as having the best outcomes for patients with symptomatic pancreatic necrosis. The scientific literature has confidently positioned endoscopic drainage and necrosectomy among the most effective interventions for patients with symptomatic walled off necrosis. Innovations such as the use of metallic stents, chemical debridement and multiple modalities for drainage of pancreatic necrosis show promise in improving outcomes for patients managed with endoscopic interventions.
\end{abstract}

Keywords: Pancreatitis; Pancreatitis, acute necrotizing; Debridement; Endoscopy; Stents

\section{INTRODUCTION}

Acute pancreatitis (AP) ranks among the most common causes for gastrointestinal disease related hospital admissions [1]. Pancreatic necrosis complicates AP in up to $15 \%$ to $20 \%$ of patients. Defined as necrotic, non-viable pancreatic tissue, it is diagnosed by the regional absence of enhancement within the pancreas on contrast enhanced cross sectional imaging studies such computed tomography (CT) or Magnetic resonance imaging [2-4].

Pancreatic necrosis often involves the pancreatic and peri-pancreatic tissues ( $75 \%$ to $80 \%$ ) and associates with local (e.g., biliary stricture, portosplenomesenteric venous thrombosis) and systemic complications (transient and persistent organ failure) of AP [4-6]. The overall mortality of AP is approximately $5 \%$; whereas the rate of mortality increases to $17 \%$ in patients with necrotizing pancreatitis [3]. Infected pancreatic necrosis ultimately complicates $20 \%$ of cases of necrotizing pancreatitis. When pancreatic necrosis becomes infected there is a significantly higher risk for mortality, 30\% compared to $12 \%$ in sterile necrosis [3]. Infected pancreatic necrosis often manifests days to weeks from onset of AP symptoms and should be suspected in the setting of significant clinical deterioration, new systemic inflammatory response syndrome(SIRS), positive blood culture testing and/or the presence of intra-parenchymal gas on cross sectional imaging $[4,7]$. The gold standard for diagnosis of infected pancreatic necrosis is confirmation by CT or ultrasound guided fine needle aspiration (FNA) for culture. While the specificity for sampling is 90\%; the false negative rate is not insignificant at $20 \%$ to $25 \%$ [4]. Due to limitations in accuracy and the potential to introduce microorganisms and infect an otherwise sterile 
fluid collection many centers do not routinely perform FNA of pancreatic necrosis. In practice, many centers treat suspected pancreatic necrosis empirically with antibiotics which provide gram negative coverage and/or antifungal agents based on clinical suspicion. Adjunct tests such as serum biomarkers of inflammation(C-reactive protein, white blood cell count) and procalcitonin (sensitivity 0.90 and specificity 0.89 in the absence of co-infection) may aide in decision making for empiric therapy for suspected infected pancreatic necrosis [4].

The decision making involved in selecting the optimal management strategy for a patient with pancreatic necrosis incorporates such considerations as: timing of interventions during the natural history of AP (early vs. late phase), morphology and location of necrosis and necrotic collections, patient symptoms, comorbidities and clinical status. A strategy that incorporates a combination of minimally invasive interventions timed after a patient recovers from the acute phase of pancreatitis is now supported by prospective, randomized trials for patients with symptomatic pancreatic necrosis. Minimally invasive interventions now have strong evidence that support not only their effectiveness, but report superior outcomes in terms of risk for morbidity and complications. Endoscopic drainage and necrosectomy is an effective, minimally invasive intervention for patients with symptomatic necrotic fluid collections of the pancreas. In the setting of recent refinements in the equipment and technique, endoscopic therapy is rapidly gaining traction among institutions that care for patients with pancreatic necrosis. The aim of this article is to outline the state of the evidence for the minimally invasive management of pancreatic necrosis and the role of endoscopic therapy in this setting.

\section{MANAGEMENT OF PANCREATIC NECROSIS DURING THE ACUTE PHASE OF PANCREATITIS}

The initial strategy for management of pancreatic necrosis aligns with management strategies for AP. Supportive care is the hallmark of management during the acute phase of pancreatitis (first 1 to 2 weeks). This strategy includes aggressive fluid resuscitation timed early in the course of AP (first 48 to 72 hours), support of failing organs and early initiation of nutrition support with a preference for enteral over parenteral nutrition $[4,8]$. Invasive interventions should be deployed judiciously and with a clear therapeutic target during the acute phase of pancreatitis. For example, early endoscopic retrograde cholangiopancreatography (ERCP) improves outcomes in patients with biliary pancreatitis complicated biliary obstruction or cholangitis [9].

\section{INDICATIONS FOR AND TIMING OF INTER- VENTIONS FOR PANCREATIC NECROSIS}

Overall, up to $40 \%$ of AP will be complicated by fluid collections. The majority of these fluid collections are unrelated to pancreatic necrosis and will resolve spontaneously [10]. The Revised Atlanta Classification is consensus system for defining complications of AP. Within this framework exists a standardized schema and nomenclature for describing pancreatic fluid collections in the setting of AP [2]. Fluid collections that complicate AP are categorized by their content (solid vs. liquid), the presence or absence of a defined wall and whether they arise in the setting of pancreatic necrosis (Fig. 1) [2]. Accurately categorizing pancreatic fluid collections after AP is important as the natural history varies by the type of collection. For example, while acute peripancreatic fluid collections usually complicate interstitial pancreatitis they infrequently mature into a pseudocyst. Acute necrotic collections (ANC) are the early consequence of necrotizing pancreatitis and will very often transition to walled off pancreatic necrosis (WON).

Interventions for fluid collections are indicated only if they are symptomatic. Symptoms usually are attributable to infection (as described above) or compression of juxtaposed anatomic structures (gastric outlet, intestine, colon, bile duct, vascular structures) by the fluid collection $[4,10]$. Sterile necrotic fluid collections often require intervention when they cause chronic visceral symptoms such as nausea, vomiting, anorexia, and/or abdominal pain. Options for intervention are based on their location within the abdomen and maturity of the necrotic collection (ANC vs. WON) (Table 1). Invasive interventions targeting ANC include percutaneous drainage (PCD) by interventional radiology and surgical debridement via video assisted retroperitoneal approach (VARD) or laparotomy. However, there is substantial 


\section{KJIM}

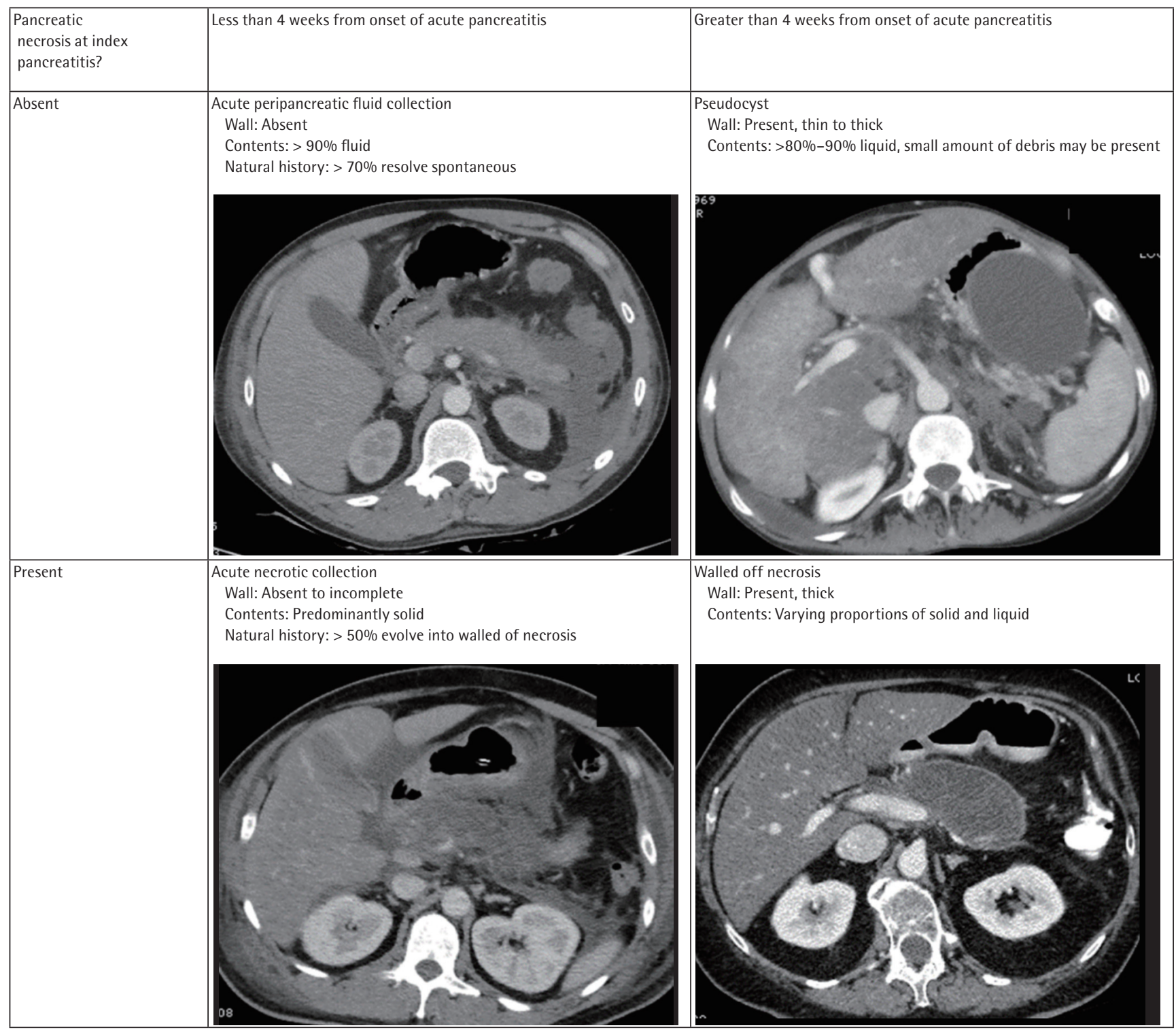

Figure 1. Classification of pancreatic fluid collections in the setting of acute pancreatitis.

literature that argues for delay of surgical interventions in patients with pancreatic necrosis and ANC until they recover from the acute phase of pancreatitis and their collections mature into WON. One retrospective analysis of more than 50 patients managed with laparotomy and necrosectomy for pancreatic necrosis demonstrated greater than $50 \%$ mortality for early ( $<2$ weeks) surgery versus $30 \%$ for surgery performed at a greater time interval [11]. The relationship between delaying invasive interventions such as surgery for necrosis and mortality is further highlighted in other retrospective studies. One study demonstrated a graduated decrease in mortality as surgical intervention were able to be delayed from less than 2 weeks ( $75 \%$ ) to $2-4$ weeks ( $45 \%)$, and greater than 4 weeks, $(<10 \%)$ from admission. A systemic review of 11 surgical series that including 1,100 patients found similar, superior outcomes when surgery was successfully delayed in patients $[12,13]$. However, there are discrete clinical scenarios that complicate pancreatic necrosis and obligate early surgical intervention: abdominal compartment syndrome and colonic ischemia.

There is a multifaceted biologic rationale for delay of 
Table 1. Options for the management of symptomatic pancreatic necrosis

\begin{tabular}{|c|c|c|c|c|c|}
\hline Technique & $\begin{array}{l}\text { Considerations for } \\
\text { patient selection }\end{array}$ & ANC & WON & Advantages & Disadvantage \\
\hline $\begin{array}{l}\text { Percutaneous } \\
\text { drainage (PCD) }\end{array}$ & $\begin{array}{l}\text { Collections are } \\
\text { ideally localized } \\
\text { to the body/tail } \\
\text { of the pancreas } \\
\text { (retroperitoneal) }\end{array}$ & $X$ & $X$ & $\begin{array}{l}\text { May control sepsis } \\
\text { Will obviate need for surgery in } \\
\text { approximately } 30 \% \text { of patients } \\
\text { Can be combined with other } \\
\text { minimally invasive techniques } \\
\text { (TED, DEN, surgery) }\end{array}$ & $\begin{array}{l}\text { High rate of fistula (>30\%) } \\
\text { Multiple procedures required } \\
\text { Low success rate when used } \\
\text { alone } \\
\text { May require significant length } \\
\text { of time (> 30 days) to resolve } \\
\text { collections }\end{array}$ \\
\hline $\begin{array}{l}\text { Endoscopic } \\
\text { drainage (TED) } \\
\text { and necrosectomy } \\
(\mathrm{DEN})\end{array}$ & $\begin{array}{l}\text { Collection(s) must } \\
\text { be adjacent to the } \\
\text { gastric or duodenal } \\
\text { wall } \\
\text { Collections should } \\
\text { be retroperitoneal } \\
\text { Collections must } \\
\text { be mature with a } \\
\text { discernable wall }\end{array}$ & & $X$ & $\begin{array}{l}\text { High technical success rate } \\
\text { Comparable outcomes to } \\
\text { minimally invasive surgery } \\
\text { in select patients with shorter } \\
\text { length of stay and recovery time } \\
\text { following interventions } \\
\text { Can create multiple points } \\
\text { of transluminal access and } \\
\text { drainage } \\
\text { Can be combined with other } \\
\text { modalities (PCD, VARD) } \\
\text { Tolerated by patients with } \\
\text { significant comorbidities }\end{array}$ & $\begin{array}{l}\text { Multiple procedures required } \\
\text { (median, } 3-7) \\
\text { High rate of complications } \\
(>20 \%-25 \%) \\
\text { Access to distant abdominal } \\
\text { collection is limited }\end{array}$ \\
\hline $\begin{array}{l}\text { Minimally } \\
\text { invasive surgery: } \\
\text { Video assisted } \\
\text { retroperitoneal } \\
\text { debridement } \\
\text { (VARD) } \\
\text { Laparoscopic } \\
\text { necrosectomy/ } \\
\text { cystgastrostomy }\end{array}$ & $\begin{array}{l}\text { Collection(s) must be } \\
\text { localized to body/ } \\
\text { tail for VARD } \\
\text { Collection(s) } \\
\text { must be mature } \\
\text { for laparoscopic } \\
\text { approaches }^{\mathrm{a}}\end{array}$ & $X$ & $\mathrm{X}$ & $\begin{array}{l}\text { Limited peritoneal } \\
\text { contamination } \\
\text { Lower length of stay and } \\
\text { mortality } \\
\text { Can be combinded with other } \\
\text { techniques (PCD, DEN, TED) } \\
\text { Single stage procedure in many } \\
\text { patients }^{\mathrm{a}} \\
\text { Access to extra pancreatic, } \\
\text { peritoneal collections }{ }^{\mathrm{a}} \\
\text { Simultaneous cholecystectomy } \\
\text { in biliary pancreatitis patients }\end{array}$ & $\begin{array}{l}\text { Multiple procedure required } \\
\text { Limited access to peri- } \\
\text { pancreatic, distant abdominal } \\
\text { collections } \\
\text { Peritoneal contamination } \\
\text { Risk for post-operative fistula } \\
\text { Scarring can hinder } \\
\text { re-intervention }\end{array}$ \\
\hline $\begin{array}{l}\text { Surgical } \\
\text { laparotomy }\end{array}$ & $\begin{array}{l}\text { Outcomes improve } \\
\text { with delaying } \\
\text { surgery beyond } \\
\text { the acute phase of } \\
\text { pancreatitis } \\
\text { Better outcomes } \\
\text { when interventions } \\
\text { performed for WON } \\
\text { rather than ANC }\end{array}$ & $X$ & $X$ & $\begin{array}{l}\text { Potentially single stage } \\
\text { procedure } \\
\text { Can address comorbid } \\
\text { complications (bile duct } \\
\text { obstruction, gastric outlet } \\
\text { obstruction, colonic ischemia, } \\
\text { abdominal compartment } \\
\text { syndrome) }\end{array}$ & $\begin{array}{l}\text { Higher rate of incisional } \\
\text { complications and fistula } \\
\text { Higher rate of post-operative } \\
\text { systemic inflammatory } \\
\text { response and organ failure } \\
\text { Increased length of } \\
\text { hospitalization and recovery } \\
\text { interval } \\
\text { Increased rates of PEI, diabetes }\end{array}$ \\
\hline
\end{tabular}

' $\mathrm{X}$ ' designates the most appropriate setting for deployment of an intervention (ANC vs. WON).

ANC, acute necrotic collection; WON, walled off pancreatic necrosis; TED, transmural endoscopic drainage; DEN, direct endoscopic necrosectomy; PEI, post-operative pancreatic exocrine insufficiency.

${ }^{a}$ Designates attributes unique to laparoscopic surgical approaches. 
invasive interventions for pancreatic necrosis. Focusing on supportive care and nutrition for a patient during the acute phase of AP affords time for the stabilization and/ or resolution of early systemic complications such as organ failure. This strategy allows time to optimize the patient's candidacy for anesthesia, administer nutrition to enhance wound healing after interventions and creates a better set of circumstances for a patient to cope with complications of invasive interventions (e.g., infection, bleeding, fistula) should they arise. Manipulation of necrotic pancreatic tissue and the tissue injury that occurs from drainage and debridement interventions also have the potential to further destabilize a patient through a cascade of cytokine release, new SIRS and potentially new organ failure. This scenario is best tolerated when the patient has recovered from the acute phase of pancreatitis [12-14].

Delay also affords the necessary time for debris, fluid and devitalized tissue within and surrounding the pancreas to either resorb or organize. When ANC organizes into structures with discrete borders (WON), it is easier to delineate viable and nonviable tissue. These collections are more amenable to drainage and debridement [15]. Furthermore delay of invasive interventions is believed to limit blood loss and inadvertent damage to viable pancreatic tissue. This strategy may also decrease the rate of postoperative endocrine and exocrine pancreatic insufficiency [16]. Finally, ANC and WON when less than $6 \mathrm{~cm}$ may decrease in size or resolve completely given enough time. In patients that are asymptomatic or minimally symptomatic an approach of expectant management without intervention may be reasonable $[17,18]$.

\section{THE "STEP UP" APPROACH FOR THE MINI- MALLY INVASIVE MANAGEMENT OF PANCRE- ATIC NECROSIS}

Open surgical necrosectomy via laparotomy was once the standard for managing pancreatic necrosis. High quality evidence now supports minimally invasive therapies for the management of pancreatic necrosis. These approaches include: endoscopic drainage and necrosectomy, PCD utilizing radiology guided catheters and surgical debridement utilizing a VARD or laparoscopic approaches (Table 1) [7]. Selecting among the variety of interventions for the management of an ANC or WON is a complex decision best made in a multidiscipline setting. While expertise among each of these interventions may vary between centers, these interventions are best undertaken by experienced physicians at centers with strong support from complimentary specialties such as interventional endoscopy, hepatobiliary surgery and interventional radiology (IR). High quality contrast enhanced imaging is critical for decision making when selecting the optimal therapeutic approach for a patient with ANC and WON. Selecting among minimally invasive interventions is a nuanced process that incorporates such details as the size, location, characteristics and point in the natural history (maturity) of the necrotic collection. Following the initiation of interventions careful surveillance and close follow-up is necessary to gauge not only success, but to evaluate for complications and manage the co-morbid conditions that associate with symptomatic pancreatic necrosis (e.g., malnutrition).

A landmark multicenter, randomized trial compared traditional (open) necrosectomy with a tiered approach utilizing a sequence of minimally invasive techniques to stabilize and manage patients with infected pancreatic necrosis was published by the Dutch Pancreatitis Study Group (van Santvoort et al. [19]) in 2010. The Patients with Acute Necrotizing Pancreatitis (PANTER) trial randomized 88 patients with infected pancreatic necrosis to traditional open necrosectomy or a 'step-up' approach. The "step-up" approach involved a sequence of PCD of the infected necrotic collection(s) for source and symptom control followed by VARD with postoperative lavage for surgical debridement if symptoms persisted.

Of the patients managed with a step-up approach, $35 \%$ of the patients did not ultimately require surgery and were successfully managed with PCD alone. Of "stepup" patients, 60\% ultimately required surgery with the majority managed with VARD. Of these patients only $33 \%$ required multiple surgical procedures. The rate of development of new multiple organ failure after intervention ( $12 \%$ vs. $40 \%, p=0.002$ ) and composite endpoint of major complications or death ( $40 \%$ vs. $69 \%, p=0.006$ ) was significantly lower in the group managed with a minimally invasive, step-up approach compared with the open necrosectomy group. The authors also calculated a costs savings of $\$ 16,000$ US per patient with a 
step-up approach over open surgery for infected pancreatic necrosis [14]. These investigators reported long term outcomes ( 86 months, mean follow-up) from this trial [20]. The step-up group was found to have significantly lower rates of incisional hernia (23\% vs. $53 \%, p=$ $0.004)$, pancreatic exocrine insufficiency (29\% vs. $56 \%$, $p=0.03$ ) and endocrine insufficiency (40\% vs. $64 \%, p=$ 0.05 ). There was no difference between groups in terms of need for repeat interventions.

In a pilot study (Endoscopic transgastric versus primary necrosectomy [PENGUIN] trial) this same group of Dutch investigators compared step up approaches that either incorporated endoscopic interventions or surgery as destination therapy for the management of symptomatic infected pancreatic necrosis [21]. Patients $(n=22)$ were randomized to either surgical versus endoscopic 'step-up' approaches. Destination interventions (endoscopic therapy or surgery) were successfully delayed to an average of 50 days from symptom onset with this approach. Of the patients $(\mathrm{n}=12)$ randomized to the surgery arm, 10 ultimately required surgical intervention with retroperitoneal debridement $(n=6)$ or open laparotomy $(n=4)$. Of the patients randomized to endoscopic therapy $(n=10)$, two of these patients failed an endoscopic approach and required retroperitoneal surgical debridement. A significantly lower composite endpoint of overall complications and death were found in the endoscopic therapy group ( $20 \%$ vs. $80 \%, p=0.03$ ), including lower rates of postprocedure organ failure ( $0 \%$ vs. $50 \%, p=0.03$ ). Need for pancreatic enzymes supplementation was also lower at 6 months following discharge in the endoscopic therapy group (o\% vs. 30\%, $p=$ o.04). A larger, multicenter trial evaluated minimally invasive surgical versus endoscopic "step up" approaches [14]. Powered to evaluate a composite endpoint of major complications or death at six months between groups, 98 patients were randomized in the study comprising 19 collaborating centers. While no differences were found in composite endopoint ( $43 \%$ vs. $45 \%, p=0.88$ ) or mortality (18\% vs. $13 \%, p=0.50$ ) between endoscopic and surgical "step up" groups, the rate of pancreatic fistula and length of hospitalization was lower with an endoscopic "step-up" approach. A recent meta-analysis evaluating data from three randomized studies ( $\mathrm{n}=190$ patients) compared (predominantly) minimally invasive surgery techniques to endoscopic therapy for infected pancre- atic necrosis. An endoscopic approach was associated with a lower odds of new onset organ failure (odds ratio [OR], o.31; confidence interval [CI], o10 to 0.093), pancreatic fistula (OR, 0.09; 95\% CI, 0.03 to 0.28 ) and shorter length of hospital stay ( -7.86 days; $95 \%$ CI, -14.49 to 1.22) without differences in mortality, complications or pancreatic insufficiency [22].

Based on the available evidence from carefully designed, randomized trials a minimally invasive approach incorporating a combination of therapies offers superior outcomes compared to open laparotomy for patients with symptomatic necrosis. More recent trials have also established endoscopic therapy as legitimate option for the management of pancreatic necrosis with outcomes equivalent to approaches that rely on minimally invasive surgery in carefully selected patients.

\section{THE EVOLUTION OF ENDOSCOPIC MANAGE- MENT FOR PANCREATIC NECROSIS}

Endoscopic therapy is generally reserved for WON juxtaposed to the gastric or duodenal lumen. The earliest iteration of endoscopic therapy for the management of WON involved transmural endoscopic drainage (TED). One of the earliest reports of TED was published by Baron et al. [23]. This technique involves identifying a window for the creation of a transgastric or transduodenal conduit between the lumen and the target WON collection. This is accomplished either by identifying the site of extrinsic compression of the lumen by the juxtaposed collection on endoscopic evaluation or by utilizing endoscopic ultrasound (EUS). Transmural access into the collection is achieved via needle, needle-knife or cystotome electrocautery. A guidewire is then coiled within the collection under fluoroscopy. The tract is then dilated with a graduate catheter and a balloon (range, 8 to $20 \mathrm{~mm}$ ). Multiple 7 to $10 \mathrm{Fr}$ pigtail stents are positioned across the fistula to maintain access and drainage. A nasocystic irrigation catheter for subsequent continuous lavage ( 24 to 96 hours) may also be inserted. As the endoscopic community gained more experience and examined outcomes for managing necrotic collections with the TED technique it became clear that a significant proportion of WON failed to resolve with endoscopic drainage alone $(<50 \%)$ [24]. The challenge of managing 


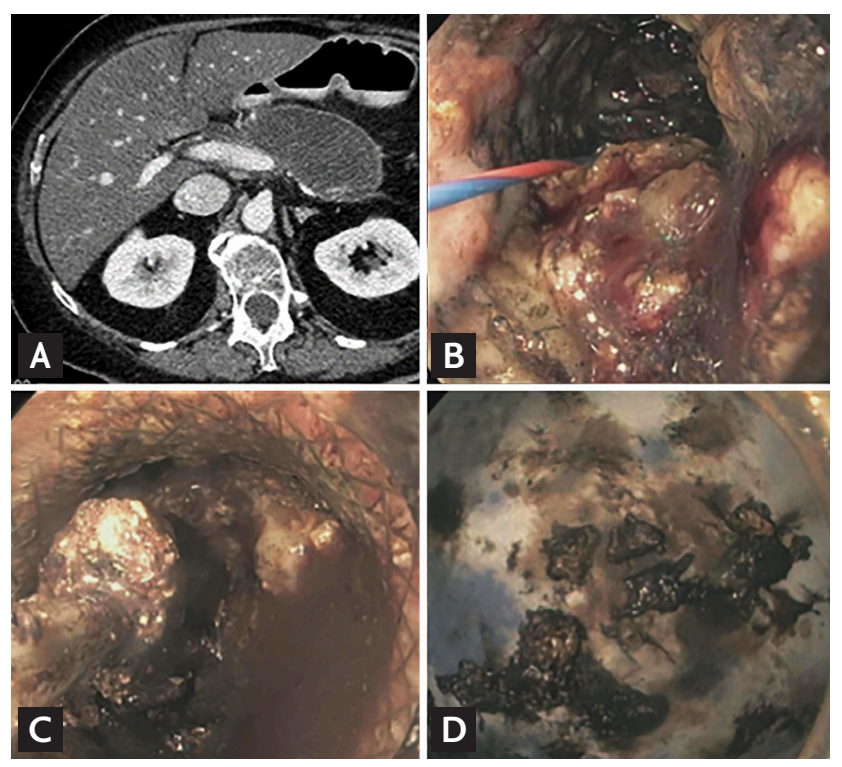

Figure 2. (A) Computed tomography scan demonstrating walled off pancreatic necrosis (WON). (B) Endoscopic view of intra-cystic necrotic tissue. (C) Direct endoscopic necrosoectomy utilizing a snare via Lumen Appposing Metallic Stent conduit. (D) Necrotic tissue extracted from the WON cavity.

WON with TED alone is that WON collections are slow to resolve and contain substantial proportions of solid, necrotic tissue. Large clumps of necrotic tissue do not readily exit through a cystgastromy tract created using pigtail stents. Consequently, rates of secondary infection and/or recurrence following intervention are high in WON with endoscopic drainage alone.

Endoscopic therapy for WON realized a significant advancement with the addition of direct endoscopic necrosectomy (DEN) (Fig. 2). A technique of endoscopic debridement, DEN maneuvers follow TED either at the same session of endoscopic drainage and/or as subsequent endoscopic debridement procedures. During DEN the transmural tract is dilated to a range of 15 to $20 \mathrm{~mm}$ to permit a forward- or side-viewing endoscope into the WON cavity. Under direct visualization, solid necrosis is dislodged by lavage with saline or dilute hydrogen peroxide $\left(\mathrm{H}_{2} \mathrm{O}_{2}\right)$ solution. Mechanical debridement and extraction of necrosis is also performed utilizing repurposed endoscopic accessories such as snares, nets, forceps and/or stone removal baskets. Early experience in the form of retrospective series demonstrated superior outcomes for resolution of WON with DEN over TED alone (88\% vs. 45\%) [24]. Large cases series re- ported treatment success for WON in $75 \%$ to $95 \%$ of the patients $[25,26]$. A technique that requires multiple procedures (median, 3 to 7 ) rates of adverse events over the course of treatments are high (10\% to $40 \%)$ with bleeding (> 20\%) and infection (15\% to $26 \%$ ) among the most common complications [25-27]. Recurrence rates for collections is reported at $<10 \%$ in large case series.

\section{RECENT INNOVATIONS IN THE ENDOSCOPIC MANAGEMENT OF PANCREATIC NECROSIS}

As the endoscopic community gained further experience with TED and DEN for WON, a number of innovations have augmented the armamentarium for endoscopic management of WON.

EUS is now considered the optimal method to identify a safe window for trans-enteric access for drainage of pancreatic fluid collections (Fig. $3 \mathrm{~A}$ and $3 \mathrm{~B}$ ). This is based on superior rates of technical success with EUS guided access approaches compared to endoscopic visualization alone $[28,29]$. While trials comparing EUS and non-EUS endoscopic access approaches report no statistically significant differences in rates of complications, it is possible that these studies are underpowered for detecting differences in rates of complications directly related to access maneuvers. The consensus among experts is that EUS offers substantial technical advantages in terms of avoiding interceding vessels and delineating juxtaposed anatomic structures. An EUS guided access approach is now the standard of care as it likely minimizes complications directly related to maneuvers for the creation of a cystenterostomy (e.g., bleeding and perforation) [10].

TED and DEN initially relied on double pigtail plastic stents (DPPS) deployed across the cystenterostomy site to maintain tract patency during and in between endoscopic sessions. DPPS require removal during DEN. Exchanges are also quite frequent when considered over the course of endoscopic therapy for a patient with WON. Biliary fully covered self-expanding metallic stents (fcSEMS) were subsequently incorporated into TED and DEN procedures with the hypothesis that their larger caliber (8-10 $\mathrm{mm}$ vs. 2-3 $\mathrm{mm}$ ) would translate into more efficient drainage of dependent fluid and the spontaneous passage of larger pieces of solid debris from a WON cavity. A larger stent diameter was also hy- 

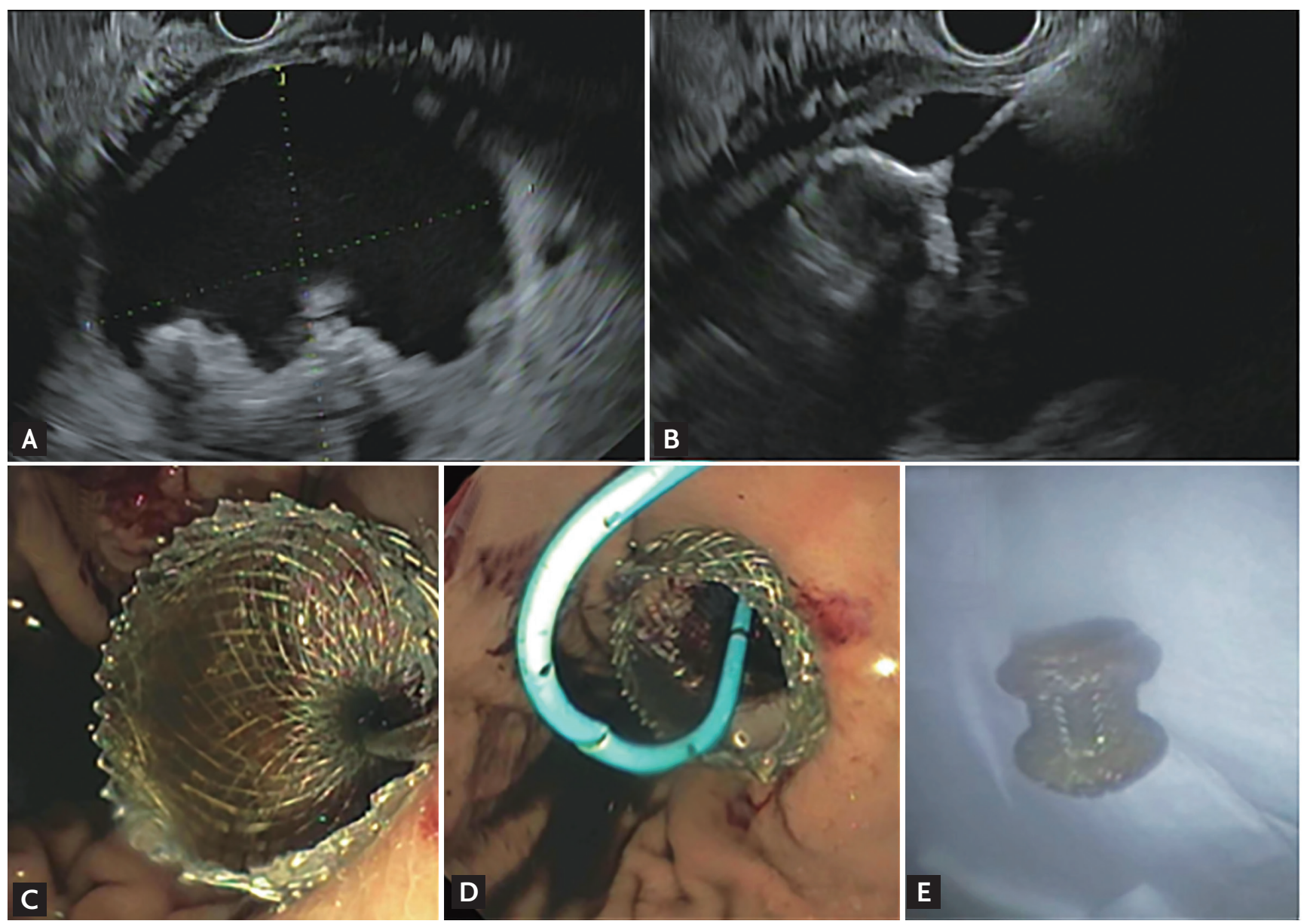

Figure 3. (A) Walled off pancreatic necrosis with layering solid debris. (B, C) Endosonographic and endoscopic views of Lumen Appposing Metallic Stents (LAMS) deployment. (D) LAMS with a coaxial pigtail stent in place. (E) LAMS extracted.

pothesized to decrease the risk of tract occlusion and secondary infection of WON. These stents also offered a technical advantage; decreasing the number repetitive complex endoscopic/fluoroscopic cystenterostomy access maneuvers associated with exchanges of the multiple DPPS during DEN sessions. Minimizing these maneuvers not only saves time during already lengthy cases and but also removes extra steps during which complications may arise (e.g., pneumoperitoneum, stent malposition). However, a systemic review evaluating 881 patients across 17 studies found no difference in overall treatment success ( $78 \%$ vs. $70 \%)$, adverse events ( $23 \%$ vs. $16 \%$ ) and recurrence of fluid collections ( $9 \%$ vs. $10 \%$ ) with metallic biliary versus DPPS [27]. Given this data, while fcSEMS offer a technical advantage during TED and DEN, there does not appear to be clear evidence that they offer interval benefit of DPPS in terms of outcomes for patients with WON.

A more recent, important innovation in TED and DEN was the development of Lumen Appposing Metallic Stents (LAMS) designed specifically for drainage and access of pancreatic fluid collections after AP (Fig. 3) [30]. The LAMS design incorporates flared, anchoring flanges that frame a smaller diameter saddle. These devices have undergone further refinements including greater saddle length $(15 \mathrm{~mm})$ to access collections at a distance of $>10 \mathrm{~mm}$ from the gastrointestinal lumen and a wider saddle lumen diameter ( 15 to $20 \mathrm{~mm}$ ) to permit both passage of larger endoscopes for debridement and egress of WON contents during and in between endoscopic treatment sessions. These refinements show promise in diminishing the number of endoscopic sessions required for endoscopic therapy of WON [31]. Perhaps the most important refinement to this platform 
was the incorporation of an electrocautery tip into the stent catheter design. This allows for creation, dilation of and LAMS deployment across a cystenterostomy tract through a seamless series of steps using the LAMS catheter alone. This last innovation not only makes the TED procedure more efficient, but eliminates a number of the complex, intervening maneuvers previously necessary to successfully create and stent a cystenterostomy tract (e.g., needle access, tract dilation with catheters and multiple balloons, repeated tract access with the guidewire for placement of $>2$ stents) [10,30]. Retrospective studies evaluating LAMS for the management of WON reported superior rates of clinical success, shorter procedure duration and need for fewer procedures when compared to DPPS [32-34]. However, a subsequent randomized trial comparing DPPS or LAMS endoscopic approaches for the management of WON reported similar rates of treatment success with no difference in number of procedures required between groups. This trial reported similar rates of readmissions and overall rate of adverse events; however, the investigators discovered a significantly higher rate of stent related adverse events in patients managed with LAMS (32.3\% vs. $6.9 \%, p$ $=0.01$ ). Bleeding related to pseudoaneurysms requiring ICU admission and transfusion occurred in 3/31 LAMS patients in this trial [35]. After review of these adverse events, an amendment to the protocol mandating earlier evaluation of the WON collections for radiographic evidence of resolution (3 weeks vs. 6 weeks) and prompt removal of the LAMS stent if indicated was made by the investigators. This resulted in no significant, further difference in adverse events between the groups. A higher rate of aneurysmal bleeding with LAMS was also reported in a retrospective study [36]. Recent data suggests that this risk of adverse events with LAMS may be ameliorated by the placement of a coaxial double pigtail stent to prevent mechanical agitation of intra-cystic vessels and stent occlusion by necrosis or tissue overgrowth [36,37]. A recent systematic review of 737 patients from nine studies found similar rates of clinical success (88.5\% vs. $88.1 \%, p=0.93)$ and adverse events $(11.2 \%$ vs. $15.9 \%, p=0.38)$ compared to DPPS [38]. Based on this data, while LAMS offer technical advantages for the endoscopic management of WON, it is unclear that this technology translates to superior outcomes for patients. This should be weighed carefully against the interval ex- pense ( $\$ 4,000$ to 5,000 USD) of LAMS stents. Additional prospective trials are necessary to understand the comparative effectiveness, optimal setting and best practices for use of DPPS, fCSEMS, and LAMS for the endoscopic management of WON.

Chemical debridement with lavage of $>200 \mathrm{~mL}$ of $3 \%$ $\mathrm{H}_{2} \mathrm{O}_{2}$ solution (1:5 to 1:20 dilutions) is reported to enhance the efficiency of WON drainage and necrosectomy procedures in non-comparative case series [39-41]. The effervescent action of $\mathrm{H}_{2} \mathrm{O}_{2}$ solution is hypothesized to aid in the dislodgement and expulsion of necrotic tissue over hours and days after instillation. While no complications directly related to instillation of $\mathrm{H}_{2} \mathrm{O}_{2}$ solution into WON have been reported in published cases series, a theoretical risk of air embolization may give operators pause in fully embracing this technique. Comparative studies are necessary to gauge the interval benefit of this adjunct therapy.

\section{NOVEL APPROACHES FOR THE ENDOSCOPIC MANAGEMENT LARGE AND COMPLEX WON COLLECTIONS}

Collections that are large $(>12 \mathrm{~cm})$, loculated or contain septations are less likely to respond to the endoscopic management strategies described above [42]. The multiple transluminal gateway technique (MTGT) involves the creation of multiple endoscopic conduits into complex WON collections. By generating two to three transluminal cystenterostomy tracts and inserting a nasocystic tube into one of these multiple conduits, directional lavage expels necrotic contents out the other conduit(s). One comparative study reported a higher likelihood of treatment success with MTGT compared to conventional TED alone (OR, 9.24; 95\% CI, 1.08 to 79.02; $p=0.04$ ) when adjusting for size of the WON collections [43].

Ross et al. [44,45] published the Virginia Mason Medical Center group's unique, algorithmic multi-modality drainage approach for the management of WON. A multidiscipline combination of drainage techniques, PCD catheter(s) are inserted by their IR group and patients are immediately taken for TED [44,45]. IR catheters are subsequently, progressively upsized over the weeks and months that follow index drainage to a maximum diam- 
eter of $24 \mathrm{Fr}$. Drains are lavaged with 10 to $20 \mathrm{~mL}$ three times per day until the target WON collection(s) resolve. Patients are evaluated for disconnected pancreatic duct (DPD) with magnetic resonance cholangiopancreatography (MRCP) or ERCP. In patients with DPD a trans-enteric stent is left in place indefinitely to maintain a transmural fistula for the excluded pancreas. Outcomes after long term follow (median, 749.5 days) for this dual modality drainage (DMD) technique were published by this group in 2014. DMD was performed in this cohort at an average of 75.5 days from after onset of pancreatitis. Of the 117 patients managed with DMD, 88\% ( $n=103$ ) completed DMD and 8.5\% $(\mathrm{n}=10)$ were still undergoing treatment. A median of $\sigma_{3}$ days were required for DMD to resolve WON in patients that completed the therapy. DMD-related adverse events occurred in $3.4 \%$ of patients; none of which included fistula. Of this cohort, $3 \%$ (3/103) required surgery after completing therapy [45]. This group also published their comparative experience between PCD alone versus DMD for pancreatic necrosis. Patients undergoing DMD demonstrated a significant lower median length of hospital stay (16 days vs. 39 days), significantly fewer drains/procedures required for therapy (3 vs. 5) and fewer CT scans (8 vs. 14) required for surveillance and management. Mortality rates between the two groups were the same [46].

\section{APPROACH TO COMPLICATIONS ASSOCIATED WITH WON}

DPD occurs in the setting of pancreatic necrosis of the head, genu or body of the pancreas. Regional destruction and the consequent obstruction of the pancreatic duct is complicated by the presence of viable upstream pancreatic parenchymal that is "disconnected" from the duodenal lumen. With residual viable pancreatic tissue lacking an outlet for secretions, DPD is a substantial risk factor for recurrent fluid collections (pseudocyst) after completion of endoscopic therapy, pancreatic fistula, abdominal pain and/or recurrent AP in the sequestered segment(s) (DPD syndrome). Diagnosed with MRCP or ERCP, DPD complicates $30 \%$ to $50 \%$ of WON $[6,47]$. Duct disconnection may be bridged with a transpapillary stent; however, this intervention is successful in only a small fraction of patients [47]. Many centers will manage
DPD endoscopically by leaving a permanent indwelling transluminal plastic stent(s) for maintenance of the pancreatic-enteric fistula after completion of endoscopic therapy for WON $[45,48]$. However, the majority of patients DPD ultimately require surgical management with either cystgastrostomy, distal pancreatectomy or pancreaticojejunostomy for definitive therapy.

Biliary stricture complicates $16 \%$ of patients with pancreatic necrosis. Bile duct strictures associated with pancreatic necrosis are identified at 4 to 12 months following diagnosis of pancreatic necrosis and associate with pancreatic necrosis involving the head of the pancreas $[6,49]$. Endoscopic therapy is technically feasible at the time of diagnosis in $68 \%$ of patients and affords definitive treatment in $83 \%$ of these patients with a median time for stricture resolution of 6 months.

\section{CONCLUSIONS}

Pancreatic necrosis is a common complication of AP and associates with severity. The natural history of large necrotic pancreatic fluid collections often involves a transition from ANC to WON. When possible invasive interventions for necrotic fluid collections should be delayed until patients recover from the acute phase of pancreatitis and collections mature into WON as this strategy associates with superior outcomes. A minimally invasive approach for pancreatic necrosis that avoids early laparotomy is supported by data from multiple, randomized trials. Endoscopic drainage (TED) with DEN are well studied and effective interventions for WON and have an important role in the multidiscipline management of pancreatic necrosis. Innovative technologies and techniques for endoscopic access and debridement of WON have aided the evolution of these techniques. However, further prospective trials are necessary to understand not only the interval effectiveness of new techniques and technologies for endoscopic drainage and debridement of pancreatic necrosis but gauge their cost effectiveness.

\section{Conflict of interest}

No potential conflict of interest relevant to this article was reported. 


\section{REFERENCES}

1. Peery AF, Crockett SD, Murphy CC, et al. Burden and cost of gastrointestinal, liver, and pancreatic diseases in the United States: update 2018. Gastroenterology 2019;156:254272.

2. Banks PA, Bollen TL, Dervenis C, et al. Classification of acute pancreatitis 2012: revision of the Atlanta classification and definitions by international consensus. Gut 2013;62:102-111.

3. Pandol SJ, Saluja AK, Imrie CW, Banks PA. Acute pancreatitis: bench to the bedside. Gastroenterology 2007;132:1127-1151.

4. Arvanitakis M, Dumonceau JM, Albert J, et al. Endoscopic management of acute necrotizing pancreatitis: European Society of Gastrointestinal Endoscopy (ESGE) evidence-based multidisciplinary guidelines. Endoscopy 2018;50:524-546.

5. Easler J, Muddana V, Furlan A, et al. Portosplenomesenteric venous thrombosis in patients with acute pancreatitis is associated with pancreatic necrosis and usually has a benign course. Clin Gastroenterol Hepatol 2014;12:854862.

6. Maatman TK, Roch AM, Ceppa EP, et al. The continuum of complications in survivors of necrotizing pancreatitis. Surgery 2020;168:1032-1040.

7. Easler JJ, Zureikat A, Papachristou GI. An update on minimally invasive therapies for pancreatic necrosis. Expert Rev Gastroenterol Hepatol 2012;6:745-753.

8. Baron TH, DiMaio CJ, Wang AY, Morgan KA. American Gastroenterological Association clinical practice update: management of pancreatic necrosis. Gastroenterology 2020;158:67-75.

9. Fogel EL, Sherman S. ERCP for gallstone pancreatitis. N Engl J Med 2014;370:1956.

10. Elmunzer BJ. Endoscopic drainage of pancreatic fluid collections. Clin Gastroenterol Hepatol 2018;16:1851-1863.

11. De Waele JJ, Hoste E, Blot SI, et al. Perioperative factors determine outcome after surgery for severe acute pancreatitis. Crit Care 2004;8:R504-R511.

12. Besselink MG, Verwer TJ, Schoenmaeckers EJ, et al. Timing of surgical intervention in necrotizing pancreatitis. Arch Surg 2007;142:1194-1201.

13. Besselink MG, van Santvoort HC, Witteman BJ, Gooszen HG; Dutch Acute Pancreatitis Study Group. Management of severe acute pancreatitis: it's all about timing. Curr Opin Crit Care 2007;13:200-206.
14. van Brunschot S, van Grinsven J, van Santvoort HC, et al. Endoscopic or surgical step-up approach for infected necrotising pancreatitis: a multicentre randomised trial. Lancet 2018;391:51-58.

15. Amano H, Takada T, Isaji S, et al. Therapeutic intervention and surgery of acute pancreatitis. J Hepatobiliary Pancreat Sci 2010;17:53-59.

16. Uhl W, Warshaw A, Imrie C, et al. IAP guidelines for the surgical management of acute pancreatitis. Pancreatology 2002;2:565-573.

17. Rana SS, Bhasin DK, Reddy YR, et al. Morphological features of fluid collections on endoscopic ultrasound in acute necrotizing pancreatitis: do they change over time? Ann Gastroenterol 2014;27:258-261.

18. Easler J, Papachristou GI. The morphologic evolution of necrotic pancreatic fluid collections and their management. Asymptomatic: delay, defer and don't panic! Ann Gastroenterol 2014;27:191-192.

19. van Santvoort HC, Besselink MG, Bakker OJ, et al. A stepup approach or open necrosectomy for necrotizing pancreatitis. N Engl J Med 2010;362:1491-1502.

20. Hollemans RA, Bakker OJ, Boermeester MA, et al. Superiority of step-up approach vs open necrosectomy in longterm follow-up of patients with necrotizing pancreatitis. Gastroenterology 2019;156:1016-1026.

21. Bakker OJ, van Santvoort HC, van Brunschot S, et al. Endoscopic transgastric vs surgical necrosectomy for infected necrotizing pancreatitis: a randomized trial. JAMA 2012;307:1053-1061.

22. Haney CM, Kowalewski KF, Schmidt MW, et al. Endoscopic versus surgical treatment for infected necrotizing pancreatitis: a systematic review and meta-analysis of randomized controlled trials. Surg Endosc 2020;34:24292444 .

23. Baron TH, Thaggard WG, Morgan DE, Stanley RJ. Endoscopic therapy for organized pancreatic necrosis. Gastroenterology 1996;111:755-764.

24. Gardner TB, Chahal P, Papachristou GI, et al. A comparison of direct endoscopic necrosectomy with transmural endoscopic drainage for the treatment of walled-off pancreatic necrosis. Gastrointest Endosc 2009;69:1085-1094.

25. Gardner TB, Coelho-Prabhu N, Gordon SR, et al. Direct endoscopic necrosectomy for the treatment of walledoff pancreatic necrosis: results from a multicenter U.S. series. Gastrointest Endosc 2011;73:718-726.

26. Seifert H, Biermer M, Schmitt W, et al. Transluminal 
endoscopic necrosectomy after acute pancreatitis: a multicentre study with long-term follow-up (the GEPARD Study). Gut 2009;58:1260-1266.

27. Bang JY, Hawes R, Bartolucci A, Varadarajulu S. Efficacy of metal and plastic stents for transmural drainage of pancreatic fluid collections: a systematic review. Dig Endosc 2015;27:486-498.

28. Varadarajulu S, Christein JD, Tamhane A, Drelichman ER, Wilcox CM. Prospective randomized trial comparing EUS and EGD for transmural drainage of pancreatic pseudocysts (with videos). Gastrointest Endosc 2008;68:1102-1111.

29. Park DH, Lee SS, Moon SH, et al. Endoscopic ultrasound-guided versus conventional transmural drainage for pancreatic pseudocysts: a prospective randomized trial. Endoscopy 2009;41:842-848.

30. Itoi T, Binmoeller KF, Shah J, et al. Clinical evaluation of a novel lumen-apposing metal stent for endosonography-guided pancreatic pseudocyst and gallbladder drainage (with videos). Gastrointest Endosc 2012;75:870-876.

31. Parsa N, Nieto JM, Powers P, et al. Endoscopic ultrasound-guided drainage of pancreatic walled-off necrosis using $20-\mathrm{mm}$ versus $15-\mathrm{mm}$ lumen-apposing metal stents: an international, multicenter, case-matched study. Endoscopy 2020;52:211-219.

32. Mukai S, Itoi T, Baron TH, et al. Endoscopic ultrasound-guided placement of plastic vs. biflanged metal stents for therapy of walled-off necrosis: a retrospective single-center series. Endoscopy 2015;47:47-55.

33. Siddiqui AA, Kowalski TE, Loren DE, et al. Fully covered self-expanding metal stents versus lumen-apposing fully covered self-expanding metal stent versus plastic stents for endoscopic drainage of pancreatic walled-off necrosis: clinical outcomes and success. Gastrointest Endosc 2017;85:758-765.

34. Abu Dayyeh BK, Mukewar S, Majumder S, et al. Large-caliber metal stents versus plastic stents for the management of pancreatic walled-off necrosis. Gastrointest Endosc 2018;87:141-149.

35. Bang JY, Navaneethan U, Hasan MK, Sutton B, Hawes $R$, Varadarajulu S. Non-superiority of lumen-apposing metal stents over plastic stents for drainage of walled-off necrosis in a randomised trial. Gut 2019;68:1200-1209.

36. Brimhall B, Han S, Tatman PD, et al. Increased incidence of pseudoaneurysm bleeding with lumen-apposing metal stents compared to double-pigtail plastic stents in patients with peripancreatic fluid collections. Clin Gastro- enterol Hepatol 2018;16:1521-1528.

37. Puga M, Consiglieri CF, Busquets J, et al. Safety of lumen-apposing stent with or without coaxial plastic stent for endoscopic ultrasound-guided drainage of pancreatic fluid collections: a retrospective study. Endoscopy 2018;50:1022-1026.

38. Mohan BP, Jayaraj M, Asokkumar R, et al. Lumen apposing metal stents in drainage of pancreatic walledoff necrosis, are they any better than plastic stents? A systematic review and meta-analysis of studies published since the revised Atlanta classification of pancreatic fluid collections. Endosc Ultrasound 2019;8:82-90.

39. Siddiqui AA, Easler J, Strongin A, et al. Hydrogen peroxide-assisted endoscopic necrosectomy for walled-off pancreatic necrosis: a dual center pilot experience. Dig Dis Sci 2014;59:687-69o.

40. Abdelhafez M, Elnegouly M, Hasab Allah MS, Elshazli M, Mikhail HM, Yosry A. Transluminal retroperitoneal endoscopic necrosectomy with the use of hydrogen peroxide and without external irrigation: a novel approach for the treatment of walled-off pancreatic necrosis. Surg Endosc 2013;27:3911-3920.

41. Bansal RK, Puri R, Choudhary NS, et al. Endoscopic pancreatic necrosectomy: why scuff when you can flush the muck: make it an easy row to hoe. Endosc Int Open 2017;5:E847-E853.

42. Boxhoorn L, Fockens P, Besselink MG, et al. Endoscopic management of infected necrotizing pancreatitis: an evidence-based approach. Curr Treat Options Gastroenterol 2018;16:333-344.

43. Varadarajulu S, Phadnis MA, Christein JD, Wilcox CM. Multiple transluminal gateway technique for EUS-guided drainage of symptomatic walled-off pancreatic necrosis. Gastrointest Endosc 2011;74:74-80.

44. Ross A, Gluck M, Irani S, et al. Combined endoscopic and percutaneous drainage of organized pancreatic necrosis. Gastrointest Endosc 2010;71:79-84.

45. Ross AS, Irani S, Gan SI, et al. Dual-modality drainage of infected and symptomatic walled-off pancreatic necrosis: long-term clinical outcomes. Gastrointest Endosc 2014;79:929-935

46. Gluck M, Ross A, Irani S, et al. Dual modality drainage for symptomatic walled-off pancreatic necrosis reduces length of hospitalization, radiological procedures, and number of endoscopies compared to standard percutaneous drainage. J Gastrointest Surg 2012;16:248-256. 
47. Pelaez-Luna M, Vege SS, Petersen BT, et al. Disconnected pancreatic duct syndrome in severe acute pancreatitis: clinical and imaging characteristics and outcomes in a cohort of 31 cases. Gastrointest Endosc 2008;68:91-97.

48. Rana SS, Sharma R, Sharma V, Chhabra P, Gupta R, Bha$\sin$ DK. Prevention of recurrence of fluid collections in walled off pancreatic necrosis and disconnected pancre- atic duct syndrome: comparative study of one versus two long term transmural stents. Pancreatology 2016;16:687688.

49. Maatman TK, Ceppa EP, Fogel EL, et al. Biliary stricture after necrotizing pancreatitis: an underappreciated challenge. Ann Surg 2020 Oct 19 [Epub]. https://doi. org/10.1097/SLA.0000000000004470. 